\title{
Adaptation of functional systems theory for the operative analysis of information flow
}

\author{
Margarita Panteleeva ${ }^{1, *}$, Svetlana Borozdina ${ }^{1}$ \\ ${ }^{1}$ Moscow State University of Civil Engineering, Yaroslavskoeshosse, 26, Moscow, 129337, Russia
}

\begin{abstract}
The article is dedicated to the features of the development of the information economy, which relies on high technology to further the continuity of the information flow, and therefore the business continuity of individual economic entities. In particular, the authors suggest modifying and optimizing the process of transmission and processing of data within a single marketing system based on the theory of functional systems. The authors give a description of the functioning of the info graphics model for marketing information system, which allows to structure the external input information at two flows at the first stage, and at the second - to create a database of relative indicators to forecast the activity of the company as a whole. Author research was conducted in the marketing sector, a separate organization. Moreover, under the marketing researches is the systematic gathering, processing and analysis of data about issues relating to marketing products and services, competition, consumers, prices, opportunities of the company and others, oriented to specification of available data or to obtaining new information to make managerial decision. Also changes in political, legal, economical, scientific and technological, demographical and other conditions of operation of an enterprise are targets of market research.
\end{abstract}

\section{Introduction}

We hear more and more that the emergence of so-called "new economy" which functioning doesn't adhere to the general logic of classical economic theory. Many intellectual systems created by outstanding researchers and economists of the past lose the analytical importance, stop being the true instrument in development of actions of economic policy. The rising information economy found a new type of a resource - information representing at all debatability of such statement, rich type of a factor of production.

For the first time the term "information economy" appeared in the works of Stanford Center employee Mark Porat in 1976 who used this term to refer to a new branch of the economy concentrated on the modern databases and applications. These days the term "new economy" incorporates also hi-tech manufacturing which are difficult to classify as only ITsector or information-producing sector. Microelectronics, electronic mechanical engineering, instrument making, a robotics, production of the telecommunication

${ }^{*}$ Corresponding author: anteikom@yandex.ru 
equipment are all parts of these branches. The main signs separating "new economy" from traditional system, probably, should be considered the increasing rate (exceeding growth rate of GDP) of information volume gain, pressure of the financial sphere upon other sectors of economy, the transnational nature of globalization of world economy determined by pervasive property of information and the Internet. One more important aspect of modern economy is the sharp aggravation of environmental problems. The impossibility of the environment to be restored after pollution, created by an industrial civilization, and impossibility of mankind to solve this problem is a sign that the relative abundance of a new factor of production -the information - simply spreads thin both labor and capital resources, taking them away from where they are really needed. The transaction motive becomes defining in "new economy", emergence of new clusters is possible without loan of resources from former reproduction contours. It is carried out due to redistribution of effective selection of relevant information, training, financing of new quality, and then and replication of the achievements $[1,2]$

\section{Methods}

Economic science in the "new economy" is obliged to provide answers to the many issues that concern modern economists and the general public. Information creates new effects that science has not yet explained, but the actual problem lies in the fact that they themselves are subject to the effects of rapid changes, so any explanation or theory proposed by a short period may require additional research and substantial modification.

The expansion of the scope and possibilities of the information economy casts doubt on a number of dependencies, previously scientifically discovered. In particular, it refers to the concept of the A. Phillips curve. Indeed, in recent years, the US economy showed an increase in the rate of economic growth, which was $3.6 \%$ and the unemployment rate fell to $4.6 \%$, while according to the standard macroeconomic theoretical constructions noninflationary level for the US economy is $5.5 \%$. If unemployment falls below this level, according to economic theory, inflation is expected to be slightly higher than the observed values. And it just turned out to be quite low, and it did not exceed the average level of $2 \%$ per year. Thus, it must be noted that there is acceleration of economic growth with falling inflation and unemployment. In addition, it is interesting to note that the high-tech sectors of American economy saw a decrease of employed individuals, that is, in some sectors, unemployment even increased slightly. It is possible to assume that these changes are caused by just the spread of the information economy in various spheres of life and industries. $[3,4,5]$

Similar patterns of economic science has not yet been observed, and rightly associate this phenomenon with a change in the ratio of factors of production and the emergence of a special type of reproduction - the information and the corresponding sector. For the first time in decades undermined the economic development of the doctrine of its cyclical nature. The trend of becoming more like the line and takes the form of a cyclical downturn slowdown. Thereby amplitude of oscillation is certainly reduced.

If the Phillips curve is not working, it is necessary to automatically say that the instruments of economic policy, in particular monetary, should also be subject to adjustment, as, apparently, they have no independent value in the information economy, and they must be adapted to the independent dynamics of microeconomic agents today's global economy.

The information economy is a self-contained and self-sufficient force, this force increases productivity in many sectors of the economic system. In the second half of the 1990 sthe US economy showed growth in agricultural productivity by an average of $2.2 \%$, while the 25 years it increased by no more than $1 \%$ per year, while the average in other 
industries - 3.4 - $3.6 \%$. For example, one of the leading experts on the measurement of labor Robert Gordon believed that in the period between 1995 and 2000 productivity gains of the US economy were due to the exceptionally high growth rate of the production of computers, which could not but affect the whole economic system. Today, the Internet seems to have a real rival to traditional distribution channels, retail chains and supermarkets, etc. "new economy" based on computers, it reproduces itself. On the one hand, it allows you to increase productivity, improve access of the general public to the immanent social functions and benefits, but on the other - gives rise to some of the effects of which still do not exist, which change the motivation and psychology of individual and corporate, corporate behavior.

To summarize what has been said. There are many factors affecting the side of destruction, depending A. Phillips. These include: strengthening of the dollar as a reserve currency in the 1990s, the investment boom that has not led to increased costs, increased labor market mobility, allowing to restrain wage growth, changes in methods of accounting and finance, and other methods. All of the above, combined with the new institutions, emerging information economy, acting as a shock absorber, has created a new economic dynamics that require new descriptive models.

Even in 1995, Professor M. Obstfeld and K. Rogoff offered, as is often claimed, the foundation of the new macroeconomics, which allegedly deprived of deficiencies contained in the Mundell-Fleming model of an open economy. The essence of this new theory is that it considers the economy as a normal equilibrium model that takes into account the socalled "market failures" and nominal rigidities. The proposed model is based on the idea of intertemporal utility maximization of individual agents that make up the macroeconomic system. Thus, macroeconomic decisions are deterministic micro level. About this macroeconomics in general, and George wanted. Maynard Keynes, and a similar theory can be considered as a response to criticism of Robert Lucas. Asking M. Obstfeld and K. Rogoff model takes into account the imperfections of the financial markets, that is, contains significant institutional constraints. This fact serves as an undeniable advantage in the use of these models, but it does not make them perfectly suitable for all times, take into account information distortion effects of the accumulation of information and the interaction of different types of resources (we are talking about labor, capital, land, information and entrepreneurial skills). [6, 7]

It is important to consider that the information economy generates new effects associated with deviation of behavior, the nature of the available information. In other words, a growing number of behaviors, using misleading information or deliberately distorting information, economic opportunism of alleged abuses in the use of a particular relevant information about competitors, markets and technologies. Factors of production becomes even speed receipt and processing of relevant information, and an element of competition - planned disinformation.

Economic science cannot ignore these problems. Change undergo old economic category, terminological system, the interpretation of certain concepts.

With some degree of conditionality can talk about two models of business conduct - the US and Japan. If we make a comparison of these two models, for example, for the purposes of management, market strategy and the strategy of scientific research, which, in our view, are crucial components of modern Japanese and American firms, you will find the following picture. For Japanese companies as the management objectives are the increase in market share, increase in production are renewed and the third - the turnover of capital; for the US - in the first place capital turnover, followed by an increase in the value of shares, and in third place - increase in market share. (For European companies in the first place stands the turnover of capital, but in the second - extension of the product range and increasing the efficiency of production and marketing. This model takes an intermediate 
position, and therefore we cannot touch her.) Thus, the goal of US firms are reduced to short-term financial performance, focused on short-term profit, and management objectives by Japanese firms did not give priority to financial performance, but rather are focused on the product and its position in the market. For example, US companies are leaders in sales of products such as "cash cows", i.e. products that have reached maturity in the life cycle and bringing sustainable profits. Japanese firms are ahead of the US in the field of enterprise products such as the "problem", as the Japanese market psychology long-term oriented, focused on development rather than a quick profit. In Japan, compared to the US strategy in the field of research work is reduced to the pro-conducting basic research in the field of new technologies and research to develop new products. In the United States studies on the modernization and improvement of current products and to develop new technologies that have the ability to fast commercialization. That is the same system the first violin plays the pursuit of short-term profit, which determines the strategy of behavior in all other spheres of activity, in the other - the primary role for the long term, the development of all the current problems of compliance shall be verified on the basis of long-term goals. Just present dichotomy was indeed valid throughout the $1980 \mathrm{~s}$, and even to a large extent the 1990s., But at the beginning of the XXI century. competition on the possession of information orients the majority of companies in the long-term outcome, and information and technology leadership. Besides profits, as a residual index, as the approval of François Perrot could never accurately reflect the valuation of entrepreneurial skills, as it is difficult to differentiate, in any case realized monopolistic power to extract profits, and in which - implemented some capacity. Moreover, the profit may receive unfair or not the best agents. The latter effect is known representatives of evolutionary economics as hyper selection when there is a selection of negative qualities and properties and their behavior with respect to the rise of positive qualities. This effect is the basis of the deployment hreodnoy path of economic development. Advertising is a way for companies to extract additional profit, that is the information tool, providing a psychological impact on consumers, which actually reinforces the monopoly power of the company on this market share. Profit in absolute competition is absent, because the prices are equal to marginal cost. It turns out that in absolute competition, lack of entrepreneurial ability, once it receives a zero fee, or, otherwise, it gets a low score due to the structure of the market, more precisely, its shape? Maybe the very business is possible only in conditions of monopoly? These questions are obvious negative response, but a way of organizing the competition, probably, defines profit opportunities in the process of economic competition of different subjects. Information, on the one hand, virtualizes the concept of profit, but, on the other - programs the new profit opportunities. Thus, profit is a kind of synthesized concept, its formation depends on many factors. If this parameter is a collective, the attention paid to him under doctrines and theoretical models, created in economics, seems excessive and overpriced. In Russia in recent years numerous companies show zero profit or loss, that is, negative income while continuing to lead a normal economic activity, the markets are not perfectly competitive. Therefore, it is either to another method of evaluating the ability of business, or is it possible to doubt the thesis that the profit of certain valuation of these abilities. And if so, then income taxation is the most distorted, affecting diversified operations agent. In connection with this, obviously, it's best to ensure a reduction of income tax, rather than the value added tax in order to effectively solve the problem of capital, management, equity and dividend policy. [8]

Information and information asymmetries determine the state of the market. J. Stiglitz, J.Akerlof and M. Spence in 2001 was awarded the Nobel Prize in economics for his support of the functioning of markets and information distortion occurring in the markets and lead to the need for government regulation. Supporters of liberal interpret this as an attack on freedom of the individual. They argue that a significant amount of information cannot be 
structured that it is only concerned with the market, and thereby recreates the spontaneous order in accordance with which information deemed relevant.

When the state of the economic situation increases the amount of information flow (Figure 1, curve A). Information is collected and reaching the subjects of management, is the need for corrective action economic structure (curve S). Adequate response to external stimuli increases the efficiency of investment activity (curve $\mathrm{X}$ ). Once the process is stabilized (activities adjusted in accordance with the previously received information, and the new has not yet been taken into account) will be first reduced efficiency, and again increasing the amount of information (curve A begins to rise). [9]

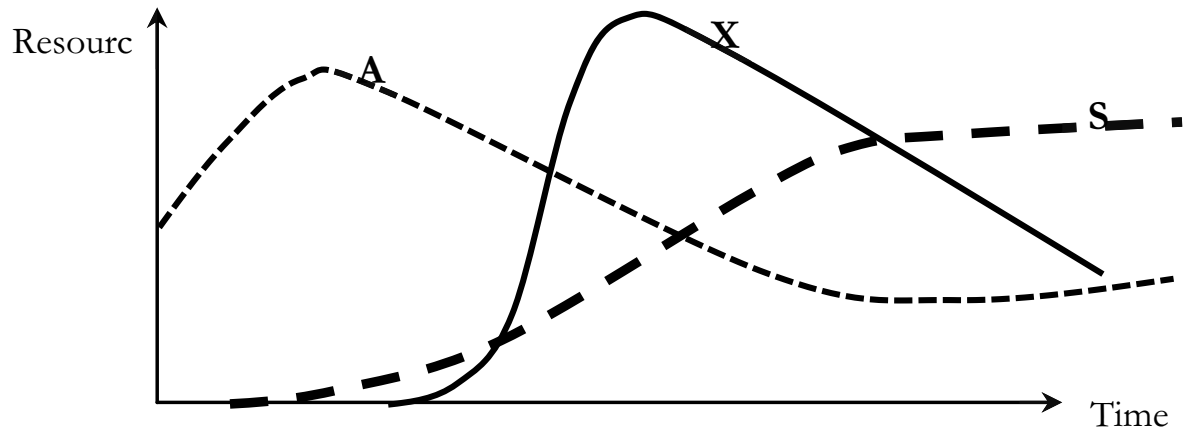

Fig.1. The dynamics of different kinds of resources and the efficiency of the investment policy.

Determination of the dynamics of the relation of these parameters allows to identify the onset of bifurcation state, and therefore, time to take appropriate decisions in order to prevent its negative effects and formation of a new efficient investment policy.

The power is determined by the ability to limit the freedom of action, the implementation of economic plans another subject of the economy, whether it be a company or a person, has the self-employed. The state is the voluntary agreement of individuals and groups on a specific limitation of its "absolute" freedom, there is a hypothetical, because it is impossible to measure the freedom to rank it in terms of "more or less". If, however, enter the scale at one end of which is to delay the zero level of freedom, but on the other - a single maximum, the chain relationships will be as follows: a complete and accessible information reduces the extent of uncertainty and means order, organization, implementation, management plans and through it - freedom if the same information is scarce and distorted, just cannot get it, we are dealing with disinformation, maximum entropy, disorganization, and, accordingly, in this case, it is difficult to talk about any freedom, collapsing all the economic plans - the maximum freedom. Thus, we want to show that freedom of information is defined and the organization, and lack of freedom disinformation and disorganization. This vision has a foundation in the theory of management of complex systems, modern economic cybernetics and information is the original model of economic power.

Social object, a person, group of people cannot be unfree due to subordination someone's orders if they are subject to a contractual basis and are able to influence the conditions of its signature, to monitor its compliance. Power in this case acts as a way to influence people about solving specific problems of society on the basis of consensus and agreement. It should, in our view, to hold another analogy between the freedom of the individual (the system), and autonomy. Endurance - the ability of a system to regulate the functions performed by it. The subject is free to the extent that it is autonomous, that is, alone can fulfill the law (agreements), while in the agreed framework. If he was not 
autonomous (free), the upper level of management would not cope with the information potential. Here freedom serves as a condition for self-organization and development of the system and the independence of parts as a whole is free parts.

Ultimately, the connection between technological and institutional structures, as well as of the behavior of economic agents determine the features of the transformation of the Russian economy and Western economies. However, according to our position key to the implementation of institutional breakthroughs that are hardly possible without a constitutional ordinances, technological advances (which, in turn, are hardly possible without the implementation of mechanisms of concentration and diffusion of innovation and encouraging investment in science and technology, institutional environment), is the information that is gained thesaurus (Knowledge + Experience), which allows economic agents to act one way or another. Particularly important concept in favor of the efficient use of the accumulated achievements. In particular, the Russian Patent Office has accumulated intellectual property of a few trillion dollars, but it is not being used, is a dead weight, since there are no conditions for the reproduction and use of intellectual capital. In Russia, the lowest level of intangible assets in the industry in Europe. [10]

Forming a full thesaurus, determining the "right" pattern of behavior depends on the relevant infrastructure and the current technological and institutional structures. What to select that remember the economic entity, and if the selection and memorization of the costs associated with? It is natural that in the present and the future, it is useful from the point of view that an entity is a utility. The knowledge and experience that are needed, according to the subject, will be selected in which there is no need - discarded and lost. Consequently, there is always a risk of losing valuable information, much later manifested in the functioning of economic entities. Thus, the evolution of economic entities, and their adaptation is a process of increasing the information level of the organization (to be more precise, the changes at this level). If the loan is tied to the criterion of the gross profit, the uniformity of the monthly turnover of the company, need to double collateral (best property) automatically innovative firms, high-tech company will not be able to get a loan, which means that innovation will remain only on paper. It will not be implemented, there is a new business idea and not turn into innovation. Similar rules are destroying the economy that directly hinder the emergence of innovators. More precisely, the innovators may appear, but in areas where there are these principles, namely in trade, oil and gas business, metallurgy, petrochemical industry, but not in the field of information technology, electronics industry, instrumentation, laser technology, quantum electronics, etc.Thus, there are institutional barriers to the development of entire areas of science and industry, bringing competitive advantages of the country. Policy destruction of high-tech industrial sectors is reduced to the adoption of legislation allowing the unimpeded flow of imported equipment, ostensibly to modernize Russian industry, having the highest depreciation of fixed assets. However, under conditions of high corruption that permeates all parts of the management of the economy in the first place, such a decision would deprive the relevant orders industries the means of production (in particular, for example, electronic engineering), and secondly, provide entry into the country equipment Used by high price, and emerged delta officials and some directors will be assigned to your personal income. The government has no solutions of a preventive nature, aimed at preventing such an outcome. Such approaches deprive the country's competitive advantages. In addition, absolutely do not use the flexible mechanism of tax knowledge-intensive sectors, allowing to create incentives for the advanced development of the information sector, the electronics industry, innovative engineering, etc. The idea is to make the transaction unprofitable due to the higher value of marginal tax rates related activities, complicating the procedures for the registration of companies such as the profile of the control measures by controlling the scale of competition rules for entry and exit from specific markets. High system, ensure the 
development of consumer trends, or create long-term benefits of a strategic nature should receive credit for the most comfortable conditions and without hindrance, including, if necessary, state guarantees or direct government lending.

As was shown above the central component of economic organization today is to work with the information and use of information systems in the management process. Since the institutional theory of organizations analyzed the relationship between the participants through the structure of incentives, motivations, methods of decision-making, creating a hierarchy of relationships, power, choice and control, to the extent this information defines the entire set of ongoing interactions. The information is not difficult to measure. There are special methods for evaluating the information density, the amount of information (capacity), storage capacity and generation. Ongoing transactions - is the exchange of information and the perception that affects the nature of the transaction - a conflict or a loyal and directly generated from this attitude of some participants to others, develop rules of behavior, motives vary and ultimately transformed the system of values. Institutional theory, to get their hands of the theory of information and combine it with the methods of analysis of the dynamics of transaction costs, offers significant opportunities for the formulation and conduct further research organizations, and with the use of mathematical apparatus (and not only the theory of games).

The company is characterized by multiple information interaction. Therefore, there is a problem of aggregation of these interactions in a single set of management of the organization. This problem is known as the problem of the integration of diverse information media company, where the information environment to understand the totality of software and hardware for processing information processes of the treatments that are written in a kind of organizational and management circuit, designed to develop and put into practice concrete decisions a particular area of life of the company. From thesaurus costs on firms it depends on the level of its operation, transaction costs, organizational efficiency, and, consequently, the market prospects. Needless to say, the benefits of information are much more important than the availability of raw materials, cheap credit, a good business partner with high quality products. Without information, the above conditions cannot be held longer. They may be a coincidence. Orderly information - this is a resource that allows you to permanently or for a long period of use of the achievements of the named as the information - the content of extension, conversion of these conditions from time to reach a permanent. Information opportunities.

To integrate heterogeneous IT environments used info graphics modeling, that is, such "data processing systems, which are based on the principles of decentralized processing of information directly at the point of origin and transfer of results through communication channels." [11]

Info graphics model is built on the assumption that there is a clear predisposition strictly certain amount of control links, information on the contours fluctuate between levels, analysis of data should take place in real time.

Since the principle of a distributed information processing, the information messages can be sent to any structural units of the organization in unlimited scale.

The criterion optimization model is the total duration of the processing and transmission of transactions on the routes of movement. This time, of course, must strive to minimize. The organization as a managed system is susceptible to changes in the three groups, which are important from the point of integration on the basis of information environments info graphics models: 1) it changes as a whole; 2) changes the structure of the administrative apparatus; 3) potential changes and document quality. Therefore, not enough action to improve the control systems of the organization. It is necessary to optimize the management structure, workflow, use filters and semantic barriers to information flows in the organization as a whole, inflowing from its environment. This is possible only on the 
basis of modeling of information processes in the organization, as well as the design of appropriate control systems as regulated information flows between object and subject of management and taken into account the diversity of both.

\section{Results}

Author research was conducted in the marketing sector, a separate organization. Moreover, under the marketing researches is the systematic gathering, processing and analysis of data about issues relating to marketing products and services, competition, consumers, prices, opportunities of the company and others, oriented to specification of available data or to obtaining new information to make managerial decision. Also changes in political, legal, economical, scientific and technological, demographical and other conditions of operation of an enterprise are targets of market research.

Manager needs to make decision in the context of extreme uncertainty: dynamic rate of exchange, changes in tax laws, fluctuating inflation, new technology, competition. It is necessary to consider multiple options when asked questions "What would happen if...?" The labor-intensive analytical work lies at the heart of an effective activity of management staff of the company - performing multivariable calculations, screening knowingly deadend decisions, assessment of possible risks, analysis and statistical treatment of survey findings, etc. However analytical work with high-performance is impossible without systems approach, which allows preventing undesired operation in the work of investmentbuilding complex. At the same time, the systems approach also has some disadvantages. Particularly at the systems approach for a long time clear methodological principles allowing to move from system methodology in total to methodology of specific activities, in this case to operation of the investment-building complex (hereafter referred to as IBC), were not developed. The theory of functional systems by academician P.K. Anokhin has the most pronounced materialist philosophy of outrunning reflection of the reality. Target function is backbone factor (providing of the operational and efficient activity of construction company), and marketing information system is associated with complex of actions of gathering, processing, analysis, estimation and dissemination of the relevant, accurate and timely data for information support of management decisions and also human and material resources required for this process. [12, 13, 14]

Currently there is a large variety of conceptual models of the Marketing Information System (hereafter referred to as MIS). Nevertheless, many authors are unanimous that MIS should include either company's internal reporting system or internal information. The main functions of this system are gathering and analysis of the relevant information about the work of individual units of the company by calculating the absolute (input) and the relative (output) indicators. Usually used indicators are not enough for the analysis and prediction of the organization generally, so there is a pressing need to replenish data array of individual units of the company with new elements.

In this article authors propose info graphic model of MIS functioning with the external incoming information (we will determine it with quantum) created based on theory of functional systems, which is used extensively in the economic functions simulation.

The essence of this model (Figure 2) is that any quantum entering and circulating inside it cannot exist in isolation from another. Always it is affected by certain environmental factors. The impact of external factors was called situational affer entation (afferent synthesis is the impact on the organization by the totality of external factors constituting a specific situation, and on its back further adaptation activity of the company is deployed) by P.K. Anokhin. Some impacts on the system (MIS) are accidental, but others (usually unexpected) provoke feedback. This feedback is in the nature of the orienting reaction, in this case there is an external information flow, which by afferent analysis turns into a 
database consisting of absolute indicators, which could lead managers to some alternative solutions, and the choice of the most effective of them depends on bringing all available data to one meter and by formation of self-existing internal systems of transmission and processing of information that to predict different conditions of a construction company at a predetermined time interval.

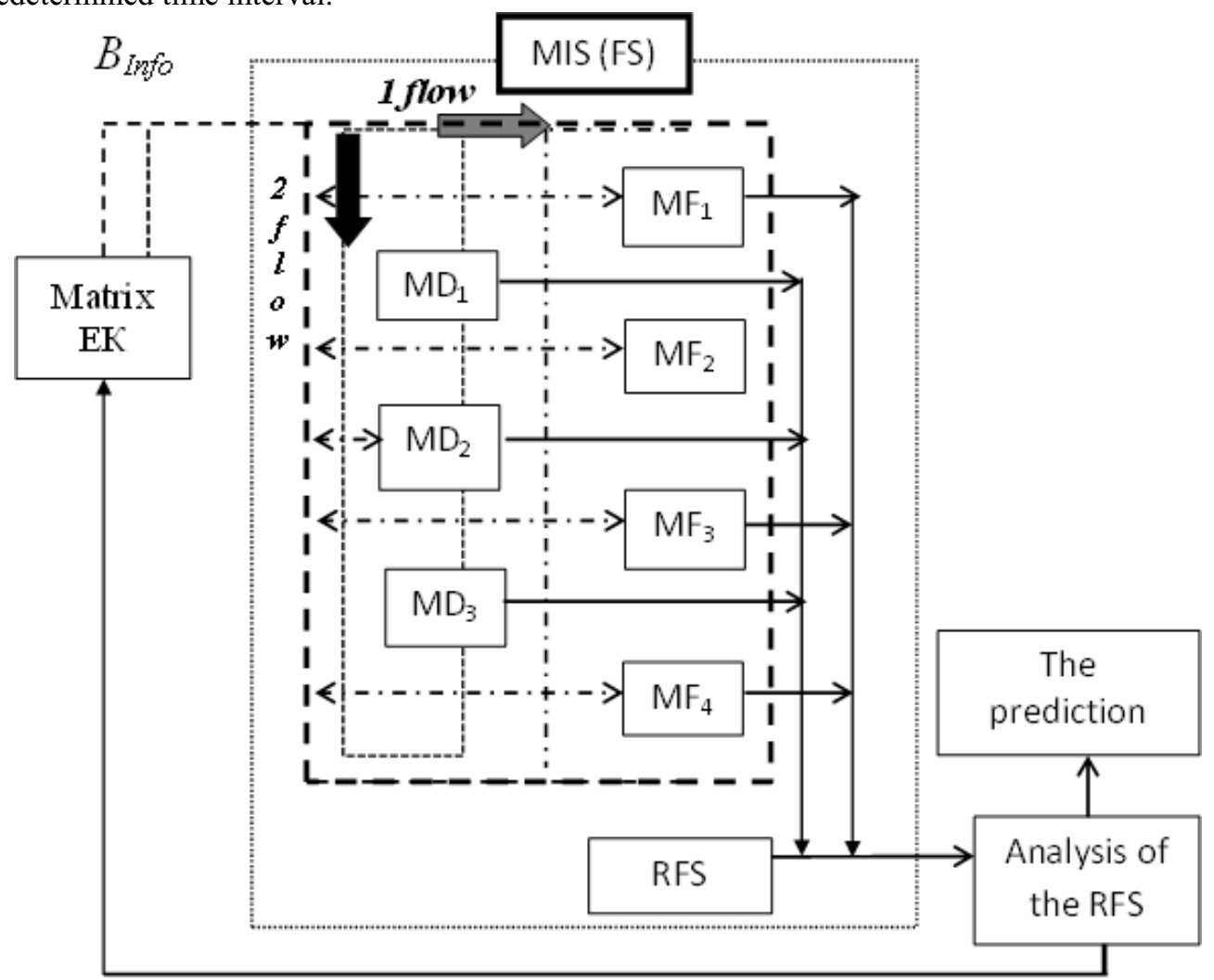

Fig. 2. Infographics model of MIS (figure created by authors). [15]

Legend for Figure 2:

$B_{\text {Info }}$-external information, represented as matrix EK;

$M I S$ - marketing information system;

$F S$ - functional system (MIS);

$R F S$ - the result of a functional system;

$M D_{i}$-the results of internal research;

$M F_{j}$ - the results of external research

\section{Discussion}

The authors propose to imagine a complex process of afferent synthesis analysis as synergistic analysis of incoming (collected) information which must be divided into two information flows, representing the result of marketing research of input information. (Binfo).

The first flow includes information collected as a result of external marketing research (Fig. 2), which is converted into relative figures in the process of collection and processing $(M F j)$. 
The second flow includes information obtained through internal marketing research (Fig. 2), which is also converted into relative figures in the process of collection and processing $\left(M D_{i}\right)$.

Each flow creates a system of relative performance indicators of internal and external reporting, shown in the Figure 2 as the matrix $S d$ and $S f$, and the data they contain is used further to predict future performance of the construction companies or IBC generally, that leads to informed management decisions and long-term plan for the development of the enterprise, taking into account existing target figures.

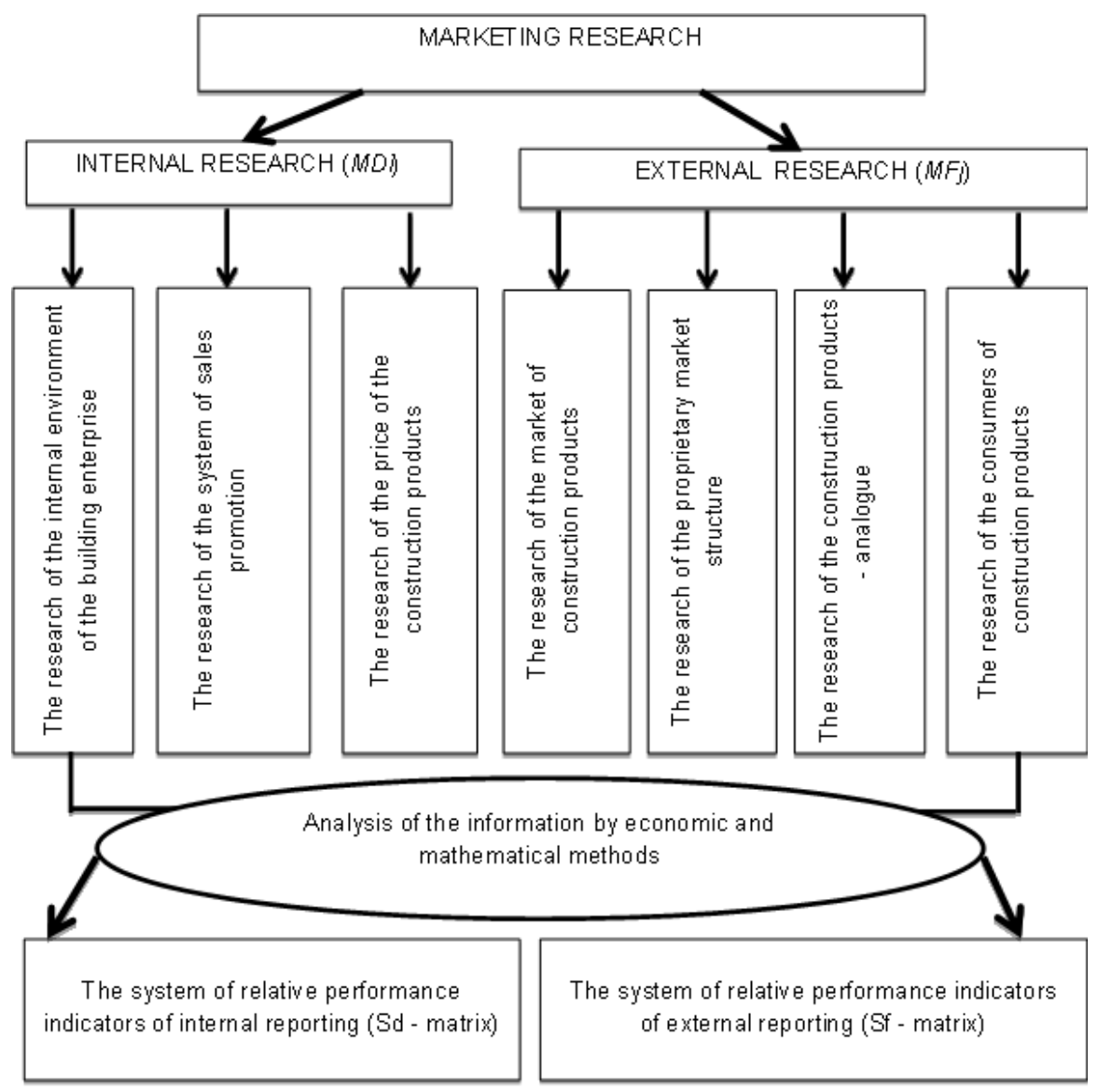

Fig. 3. The system of marketing research for building enterprise(figure created by authors).

\section{Conclusion}

Overall, the theory of functional systems allowsto build the logical flow of information coming from different sources, which become absolutely valuable tool to appraise the current status of the company in the market and predict its operations in future periods, as this flow has a flexible structure and fairly quickly can be updated with new required data.

In addition, we can confidently state that the informational approach to the theory of the firm allows you to transform the role of the administrative apparatus, the motives of its behavior, management styles that allow many decisions and procedures in an automatic mode, and at the same time increase the degree of the autonomy of the organization, 
blurring its boundaries, since access to the same information capabilities steadily leads to an averaging of the dominant role of certain individuals, groups and organizations as a whole.

\section{References}

1. M.N.Kirsanov, Scientific Herald of VSUACE. Construction and Architecture,1(29), 84$105(2016)$

2. M.A. Lunyakov, Scientific Herald of the VSUACE. Construction and Architecture, 2 (26), 36-47, (2015)

3. P.N.Kurochka, Yu.I.Kalgin, I.F. Nabiullin, Scientific Herald of VSUACE. Construction and Architecture, 1, 31-39, (2012)

4. A.A. Provorova, V.Gubina, E.V.Smirennikova, A.V.Karmakulova, L.V.E. Voronina, Economic and Social Changes: Facts, Trends, Forecast, 3 (39),56-70, (2015)

5. N.I. Antipina, Economic and Social Changes: Facts, Trends, Forecast, 2 (32), 148-157, (2014)

6. V.A.Ilyin, Economic and Social Changes: Facts, Trends, Forecast, 3 (39),9-19, (2015)

7. Z.R. Mukhametzyanov, V.N.Melkumov, Scientific Herald of VSUACE. Construction and Architecture, 4 (24), 38-47(2014)

8. S.N. Kuznetsov, Scientific Herald of VSUACE. Construction and Architecture, 4 (32), 17-24, (2016)

9. V.S. Kanhva, Jekonomikaipredprinimatel'stvo,6-3 (59-3), 821-825 (2015)

10. M.V.Kolesnikov, M.R. Kiba,Nauchnoeobozrenie, 8, 139-147 (2015)

11. M.S.Panteleeva, A.V. Unosheva, Science,Technology and Higher Education. Materials of the XI Int. research and practice conf. Strategic Studies Institute, 52-56 (2016)

12. V.O. Chulkov,Infografija. Tom 1: Mnogourovnevoeinfograficheskoemodelirovanie. Modul'nyjkurslekcij(SvR-ARGUS, Moscow, 2007)

13. V.O. Chulkov, Infografija. Infograficheskoe modelirovanie nelinejnyh virtual'nyh funkcional'nyh sistem soorganizaciidejatel'nosti (SvR-ARGUS, Moscow, 2007)

14. S.M. Borozdina, Nauchnoeobozrenie, 9, 465-471(2013)

15. S.M. Borozdina, M.S. Panteleeva, Nauchnoeobozrenie, 3, 277-280 (2013)

16. 